\title{
Another female should not sacrifice her life due to anaphylaxis following Depot Medroxyprogesterone Acetate injection - A case report
}

\author{
Illangarathna $\mathrm{YMG}^{1 *}$
}

\begin{abstract}
Introduction: Anaphylaxis is a rare complication following DMPA injection though minimizing the chance of such an occurrence should be the prime objective where it is possible. This case is considered as the first case where the diagnosis was confirmed in Sri Lanka as anaphylactic shock following the injection of DMPA (Depot Medroxyprogesterone Acetate) with the help of laboratory investigation of beta tryptase. Though the diagnosis was straight forward, many other medico-legal issues were to be addressed and this article attempts to address a few of them. Case report: Following the consented injection of the DMPA to a 24 year old mother of two children in a private small scale dispensary she collapsed with shortness of breath and chest pain. The cause of death was concluded following the post mortem examination as anaphylactic shock following the injection of DMPA. Conclusion: Related to this incident an inquiry about allergies/ asthma is also a prerequisite before the injection of drug by the doctor. Availability of an emergency tray with the expertise of emergency management should also be considered at the places where it is injected. Maintaining the cold-chain, the clear instructions about the safer brands are some other facts to be considered. This incident warns us about the importance of the proper circulars issued by the Ministry of Health related to DMPA injection.
\end{abstract}

Key words: anaphylaxis, DMPA injection, tryptase, medico-legal issues, small scale dispensaries, cheaper brands

\section{Introduction}

As a temporary contraceptive method, injection of DMPA is practiced worldwide though there are instances where minor as well as severe side effects are encountered. It has been in use in Sri Lanka for over 25 years so far. [1]Anaphylaxis is a serious systemic allergic reaction [2] that is rapid in onset and may cause death. DMPA is also reportedly had caused anaphylactic reactions, anaphylactic shock, anaphylactoid reactions and it is a rare side effect of the drug. [3, 4]According to the European drug regulatory agency are side effect means when it affects between 1 in 10,000 and 1 in 1,000 people i.e. risk is $0.01 \%$ to $0.1 \%$. [5]

Anaphylaxis is a clinical diagnosis with three diagnostic criteria [6] along with a history of recent exposure to an offending agent. When it comes to a post mortem examination and conclusion, the morphological findings are mostly non-specific if it is a rapid death. If the death is prolonged certain external and internal changes may appear which are discussed below.

${ }^{1}$ Illangarathna YMG, Consultant Judicial Medical Officer, Base Hospital, Kuliyapitiya

*Corresponding author: Illangarathna YMG, email address: illangarathna@yahoo.com
Thorough external examination plays a vital role in anaphylactic deaths following anaphylaxis as it may manifest sometimes with a rash, urticaria or angioedema. It is also important to search for the inoculated site of the allergen when it is applicable and it is for this case it is the alleged injection site. On such occasions, a sample of skin should be investigated histologically and toxicologically with a control skin sample.

The internal findings that are expected to see are as follows. [7]

i) Glottis edema and/or pharyngo-laryngeal oedema

ii) Congestion and/or pulmonary oedema

iii) Hyperinflation of the alveoli with acute emphysema

iv) Endo-luminal bronchial secretions- this finding is more frequent if there's an asthmatic factor and it's usually related to an almost immediate death

v) Haemorrhagic petechiae: suggestive of an asphyxial component of the death and it's usually associated with an almost immediate death

Microscopical examination may reveal oedema in the respiratory mucosa, discrete inflammation with 
eosinophilia, and epithelial desquamation. The number of mast cells in different organs and tissues in anaphylactic deaths not been properly evaluated.

Not only the above mentioned parameters, but mast cell tryptase is also helpful in diagnosis. Tryptase is released from the mast cell granules after anaphylaxis and it is believed that measurable amounts are found in blood, within 30 to 60 minutes. [8]

Not like in a clinical setup mast cells are tend to get degranulated and in dead bodies and as such it is difficult to identify it in postmortem tissues. But the development of immunological methods to detect and quantify mast cell proteases, especially tryptase, has made it easier to diagnose or confirm anaphylaxis in postmortems. Though analysis of tryptase level is immensely helpful, it may not be elevated when death occurs very suddenly and in deaths caused by food anaphylaxis. Further, it has been found that tryptase can be elevated in a few cases believed not to be caused by allergy. Tryptase can also be elevated with asthma, myelodysplastic syndrome, acute myelocytic leukemia, and with any condition that activates mast cells. An artifactual increase of tryptase caused by postmortem diffusion from tissues into blood is also a possibility. [9, 10]

So the diagnosis of anaphylactic shock in a dead person is a combination of above (history, clinical history, post mortem findings along with investigations). Moreover, all the other possibilities that are case specific have to be excluded. In other words, diagnosis by exclusion and diagnosis through positive evidence both should go hand in hand and then only it would acceptable as a reliable and accurate cause of death.

\section{Case report}

A 24 year old mother of two children had visited a private dispensary to take medicine for her daughter, and at that point she had decided to get her "three monthly injection" for family planning. The doctor at the dispensary had agreed to inject it and with her consent she was injected with the brand of "Depotone". Just after the injection she had come out from the dispensary but had complained of shortness of breath with tightening chest. Her mother- in- law managed to make her walk back to the doctor but she had collapsed. At that point the alleged doctor was said to have injected the victim with adrenalin and hydrocortisone. The witnessing relatives were rejecting it. The patient was immediately transported to the nearest government hospital (peripheral unit) within 10 minutes, and was managed where emergency facilities were available. With all the emergency facilities the patient was transferred to a
District General Hospital where she was pronounced dead.

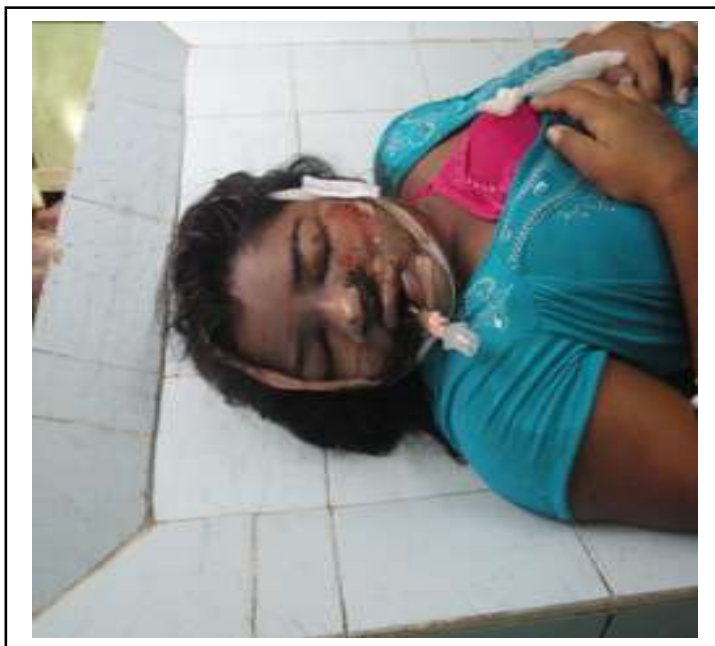

Figure 1: Obvious angioedema

Related to the post mortem findings, on external examination multiple injection sites including the DMPA injection, severe angioedema (Fig.1) of the face were noticed. Internally marked glottis oedema with pharyngeo laryngeal oedema (Fig.2) was also noted. Both lungs were hyperventilated and pale in colour. (Fig.3) Mucous plugs were seen in cut sections. No other pathology was detected macroscopically. The Immunological studies revealed Immuno CAP Tryptase level in this case was $200 \mathrm{ug} / \mathrm{L}$ while the normal range

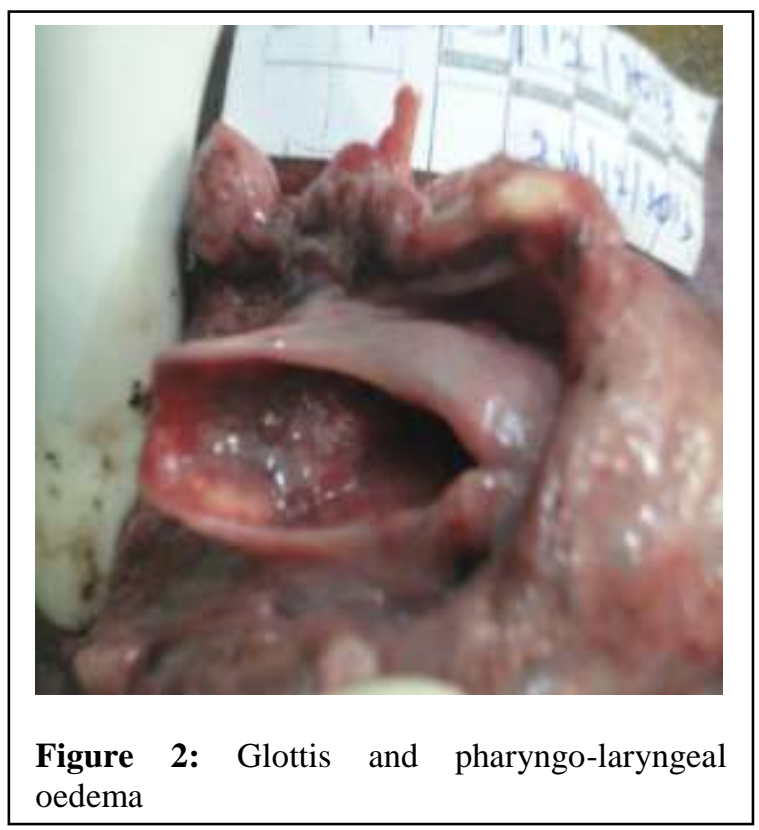


is less than $11.4 \mathrm{ug} / \mathrm{L}$. Histological examination revealed eosinophils in the liver, spleen and lungs. Lungs showed mucous with oedema.

Following the post mortem examination with all the other collaborative evidence the cause of death was concluded as anaphylactic shock following an injection of DMPA. (Depotone)

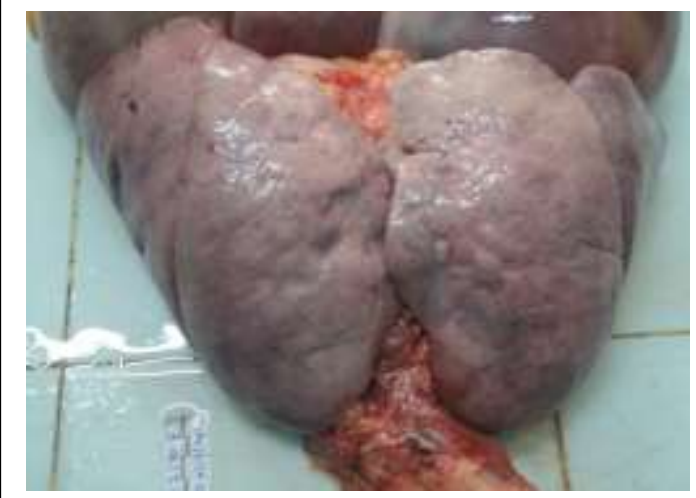

Figure 3: Hyperventilated lungs

\section{Discussion}

Formulating the cause of death was not difficult in this case though many other medico-legal issues were raised during the investigative procedure. Few such issues are discussed below.

\section{Issues related to the circulars issued by the Ministry of Health}

There were two deaths in the recent past in Sri Lanka, allegedly following the injection of DMPA. Within the Sri Lankan context by today, DMPA is a freely available drug in private and state hospitals and even in small scale dispensaries. Further to be mentioned, it is not a secret that many other varieties of DMPA injections are available to be purchased from pharmacies. (Personal experience of the author)With recent deaths occurred in a private small scale clinic and in a state clinic, the Ministry of Health took measures to impose several circulars to limit the availability of the injection so that the drug is only allowed to be injected in a place where a medical officer is available and also at only a place where emergency management facilities are available. [11] Certain brands which were allegedly causing death were also withdrawn. [1]

Instead of the above measures, it is worthwhile considering the present day scenario in Sri Lanka:

i) It is not a secret that most of the small scale dispensaries provide the facility of DMPA injections on demand by females. Small scale dispensaries do not have even an emergency tray or at least an adrenalin injection or hydrocortisone. So how can it be justifiable to give a drug with the potential of developing anaphylaxis? (The dispensary from which the DMPA injection was provided was a small scale dispensary).

ii) Many cheaper brands are illegally imported time to time to Sri Lanka. Nobody guarantees the quality of those drugs. [12]

iii) It is highly suspicious whether the cold chain is maintained or not at the pharmacies/ private clinics etc.

iv) There are no strict regulations for pharmacies about which brands are to be sold and which are not allowed for sale.

v) Pharmacists are of the opinion that they have more demand and sale for the cheaper brands and as a result they tend to sell those without thinking about the quality but the profit. (Personal communication)So no assurance is made about the brand that is injected in the private sector especially at small scale dispensaries.

With the above description one would think that it is better to ban in giving the drug in a small scale clinic. But then there will be another set of characteristic problems that has to be faced by the clients who seek DMPA injection from small scale clinics. In a way the doctors who run small scale clinics at various places render a huge service. Just imagine a situation where a client has to travel once in three months to a place where emergency management is available just for the sake of getting DMPA! It would be an added burden for a client. It might indirectly be a cause for unwanted pregnancies with other secondary complications such as increased rate of maternal deaths etc. So, it is a double edged weapon, where the stakeholders have to think deeply as to how the maximum benefit will be provided to the clients. As such the Ministry of Health should issue very clear guidelines, as to what drugs/brands are suitable and what brands should be banned. Pharmacies should be properly scrutinized to check the quality of drugs and also about maintaining the cold chain. Very clear guidelines should be issued regarding the safe places from where this drug should be injected.

Other issues encountered by the Forensic Pathologist during the investigative process

(i) According to the history given by the relatives who were the direct witnesses of the incident described that the patient was only nebulized but no injection was given at any site after giving the family planning injection by the doctor at the private dispensary. 
(ii) As the above fact was an allegation it was investigated carefully about probable injection site and following was the outcome: there were multiple injection sites encountered while performing the post mortem. But at the same time the patient had been managed at different levels i.e. firstly giving the DMPA injection to the left upper arm, then IM injection by the alleged doctor himself (but relatives denied it) at the same clinic. Following this the patient was transported to the nearest peripheral hospital where emergency management was available and at this point also many injections were given. It was a practical difficulty to be concluded in this post mortem that which injection site was made by which person.

(iii) Further the allergic history had not been inquired by the doctor beforehand according to the relatives. In incidents like this the reliable history is of prime importance to find whether the responsible doctor had followed the accepted procedure/s or not.

\section{Recommendations}

The very first thing that has to be implemented is the tight scrutinizing about the safer brands that are imported to Sri Lanka through customs. Next important point is to consider that whether the Ministry of Health has adequately recommended through circulars that which private dispensaries are allowed or considered safe for this injection.

\section{Conclusion}

When deaths are appeared to be preventable, all the possible efforts should be implemented by the responsible stakeholders. A dead person can't be given the life back, but there are many other subtle but extremely important aspects that can far easily be addressed before another death is reported with the same scenario.

\section{References}

1. Tuesday 22nd may 2012. Daily news. http://archives.dailynews.lk/2012/05/22/news55.asp [last accessed on 03-08-2016]

2. The American Academy of Allergy, Asthma \& immunology. https://www.aaaai.org/conditions-andtreatments/library/at-a-glance/anaphylaxis [last accessed on 03-08-2016]

3. Selo-Ojeme DO, Tillisi A, Welch CC, Anaphylaxis from Medroxyprogesterone acetate. Obstetrics and gynecology. 2004 May;103(5 Pt 2):1045-6

4. Depo-Provera $150 \mathrm{mg} / \mathrm{ml}$ Injectionhttps://www.medicines.org.uk/emc/medicine/1112 1[last accessed on03-08-2016]

5. http://i-base.info/qa/812.[last accessed on 03-08-2016]

6. Sampson HA, Muñoz-Furlong A, Bock SA, et al. Symposium on the definition and management of anaphylaxis: summary report. Journal of Allergy and Clinical Immunology.2005; 115:584.

7. Duarte Nuno Vieira. Forensic Medicine - From Old Problems to New Challenges.http://bscw.rediris.es/pub/bscw.cgi/d3904265/F orensic\%20Medicine\%20$\% 20$ From $\% 20$ Old $\% 20$ Problems $\% 20$ to $\% 20$ New $\% 20$ Challe nges.pdf. [last accessed on03-08-2016]

8. Simons FER, Frew AJ, AnsoteguiI J, Bochner BS, Finkelman F, Golden DBK, et al: Risk assessment in anaphylaxis: current and future approaches. Journal of Allergy and Clinical 2007;120(suppl):S2-S24.

9. Schwartz LB, Diagnostic value of tryptase in anaphylaxis and mastocytosis. Immunology and allergy clinics of North America.2006 Aug; 26(3):451-63.

10. Peter Cameron, George Jetliner, Ian Everitt. Textbook of Paediatric Emergency Medicine. Elsevier Health Sciences, 2006

11. Depoprovera injection and related issues. March 27, 2012. http://www.gmoa.lk/index.php/2012/03/depo-proverainjection-and-related-issues/. [last accessed on 03-08-2016]

12. Vials of contraceptives packed in potato containers go under the microscope. http://www.sundaytimes.lk/130505/news/vials-ofcontraceptives-packed-in-potato-containers-go-under-themicroscope-43311.html. [last accessed on 03-08-2016] 